\title{
Treatment of Hypertension with KK-25-S, a New Potent Ganglionic Blocking Agent
}

\author{
Jugoro TAKEUCHI, M.D., * Tadanao TAKEDA, M.D., \\ Koji NAKAJIMA, M.D., Takao IKEDA, M.D., \\ Eiichi UCHIDA, M.D., Shigeru YAGI, M.D., \\ Shosaku NAKAYAMA, M.D., and Hideo UEDA, M.D.**
}

Antihypertensive effect of KK-25-S, a new potent ganglionic blocking agent, was evaluated in patients with moderate to severe essential hypertension. In 7 subjects, hypotensive responses after single oral dose were tested. Significant blood pressure reduction occurred within one or 2 hours after the administration of the drug and persisted for 4 hours or more. Thirty-two patients were treated with KK-25-S for periods of 2 to 29 weeks. Seven of 9 patients treated with KK-25-S alone failed to maintain significant hypotensive effect, whereas in 20 of 26 patients who received KK-25-S combined with other hypotensive drugs, significant blood pressure reduction was maintained throughout the treatment. Side-effects of the drug due to parasympathetic blockade were seen but readily controlled. Postural hypotension was relatively infrequent and slight in degree. Comparative studies on hypotensive potencies were made among different ganglionic blocking agents. It is concluded that $\mathrm{KK}-25-\mathrm{S}$ is a potent hypotensive drug and is useful for the treatment of hypertension.

SINCE the introduction of hexamethonium ${ }^{1 /}$ and pentolinium ${ }^{2)}$ into the $\checkmark$ clinical use for the treatment of hypertention, various potent antihypertensive drugs, including several ganglionic blocking agents, have been developed and their therapeutic values have been widely recognized.

A new ganglionic blocking agent, provisionally named KK-25-S, which is one of the bis-quaternary salts containing a bicyclo- $(2,2,2)$-octane ring, was synthetized in Japan, and experimental data on its excellent pharmacologic properties have been published recently. ${ }^{3)}$ The chemical structure of the drug is, as shown below, 2-(3-dimethylaminopropyl)-3a, 4, 7, 7a-tetrahydro-4, 7-ethanoisoindoline dimethoiodide.

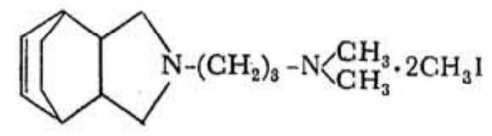
Tokyo.

From the Second Department of Internal Medicine, Faculty of Medicine, University of Tokyo,

* Associate Professor of Internal Medicine.

** Professor of Internal Medicine. 
The present study concerns our clinical trials of KK-25-S for the treatment of hypertensive cardiovascular disease. Hypotensive responses after single oral dose to 7 hypertensive subjects were estimated, and effectiveness of the drug in continuous treatment was evaluated in 32 patients with moderate to severe essential hypertention. In some of these patients, the hypotensive potency of the drug was compared quantitatively with those of other ganglioplegic agents.

\section{Materials and Methods}

Single oral dose of KK-25-S was administered to 7 hypertensive subjects. Before starting the test, patients were kept in bed for at least half an hour until appropriately stable conditions were attained. Blood pressure readings were made both in recumbent and sitting position every 10 to 60 minutes after ingestion of the drug. In 3 of the 7 patients, the tests were repeated with sufficient intervals so that observations were made 11 times in total. Dosage given ranged from $5 \mathrm{mg}$. to $40 \mathrm{mg}$. Patients were regarded as having shown significant hypotensive responses when their blood pressure reduction exceeded $20 / 10 \mathrm{~mm}$. Hg.

Thirty-two patients, 14 males and 18 females, with moderate to severe essential hypertention were treated with KK-25-S continuously for periods of 2 to 29 weeks ; duration of the treatment averaged 7.9 weeks. Their ages varied from 22 to 72 years old, with a mean of 52.4. Their initial blood pressures were greater than $180 / 100 \mathrm{~mm} . \mathrm{Hg}$ except in one juvenile hypertensive case. In 6 patients, treatment was started during hospitalization, and 26 were out-patients in our hypertensive clinic.

Control blood pressure was determined when a patient had achieved a stable blood pressure level with low salt diet and full sedation.

Initial dosage was started with 15 to $20 \mathrm{mg}$. of KK-25-S daily, which was gradually increased at weekly intervals according to patient's responses. The drug was given in 3 or 4 divided doses in most patients.

In 9 patients, treatment was begun with $\mathrm{KK}-25-\mathrm{S}$ alone; in 3 of them other hypotensive drugs were combined later. In 23 patients who had been under treatment with various antihypertensive drugs, $\mathrm{KK}-25-\mathrm{S}$ was added to the regimen. Rauwolfia alkaloids were used in all of these 26 patients with combined therapy. Fourteen patients were given hydralazine. Chlorothiazide was given in 2 cases, flumethiazide in one, hydrochlorothiazide in one, and benzydroflumethiazide in 6 patients. Four patients received Rauwolfia, hydralazine and one of those benzothiadiazine derivatives simultaneously combined with KK-25-S.

Twelve patients had been receiving other ganglionic blocking agents which were withdrawn and replaced by $\mathrm{KK}-25-\mathrm{S}$; in 14 patients $\mathrm{KK}-25-\mathrm{S}$ was later replaced by other ganglionic blocking agents. Clinical potencies of different drugs were thereby compared with each other according to the daily requirements necessary to achieve similar degree of hypotensive effect in the same patient.

In patients treated with KK-25-S alone, hypotensive effect was regarded as sufficient when blood pressure was lowered continuously more than $20 / 10 \mathrm{~mm} . \mathrm{Hg}$ below the control level or when it was maintained at a normotensive level. In patients with combined therapy, treatment was considered as effective when addi- 
tional blood pressure reduction was achieved and/or when other drugs could be reduced with satisfactory hypotensive effect maintained successfully.

\section{RESUlts}

A) Single Dose of the Oral Administration

Data on single oral dose in 7 patients are listed in Table I. Effective hypotensive responses were obtained in 5 of the 11 observations. In these cases, blood pressure began to decrease apparently within one or 2 hours after the administration of the drug; it remained at a significantly hypotensive

Table I. Blood Pressure Response after Single Oral Dose

\begin{tabular}{|c|c|c|c|c|c|c|c|c|c|}
\hline Patients & Age & Sex & $\begin{array}{c}\text { Doses } \\
\text { mg. }\end{array}$ & 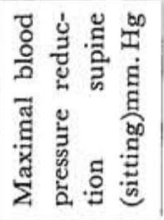 & 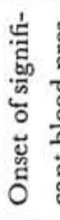 & 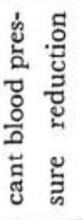 & 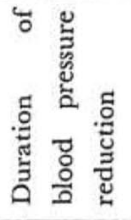 & 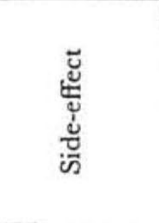 & 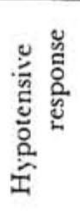 \\
\hline M. I. & 42 & F & $\begin{array}{l}15 \\
40\end{array}$ & $\begin{array}{l}10 / 5 \\
\text { unchanged }\end{array}$ & & & & weakness & - \\
\hline M. O. & 43 & M & 5 & $12 / 4(22 / 2)$ & $\left(2^{\circ}\right.$ & $\left.10^{\prime}\right)$ & $\left(\begin{array}{ll}4^{\circ} & 10\end{array}\right)$ & & $( \pm)$ \\
\hline N. K. & 63 & F & $\begin{array}{l}15 \\
30\end{array}$ & $\begin{array}{l}\text { unchanged } \\
\text { unchanged }\end{array}$ & & & & blurring of & - \\
\hline H. K. & 69 & F & 30 & $62 / 24$ & $2^{\circ}$ & $10^{\prime}$ & $23^{\circ}$ & vision & + \\
\hline C. N. & 73 & F & $\begin{array}{l}15 \\
20\end{array}$ & $\begin{array}{l}32 / 12(30 / 16) \\
36 / 34\end{array}$ & $1^{\circ}$ & $10^{\prime}$ & $\begin{aligned} & 4^{\circ} 30^{\prime} \\
< & 7^{\circ}\end{aligned}$ & & $\begin{array}{l}+ \\
+\end{array}$ \\
\hline S. E. & 22 & F & $\begin{array}{r}5 \\
15\end{array}$ & $\begin{array}{l}32 / 14(34 / 16) \\
28 / 18(48 / 20)\end{array}$ & $\begin{array}{l}1^{\circ} \\
1^{\circ}\end{array}$ & $20^{\prime}$ & $\begin{aligned} & 4^{\circ} 10^{\prime} \\
> & 6^{\circ}\end{aligned}$ & & $\begin{array}{l}+ \\
+\end{array}$ \\
\hline U. T. & 67 & M & 30 & $30 / 4(22 / 4)$ & & $30^{\prime}$ & $6^{\circ}$ & & \pm \\
\hline
\end{tabular}

level for 4 to 23 hours; maximal blood pressure reduction appeared to occur $11 / 3$ to 7 hours after ingestion of KK-25-S. Individual responsiveness to the drug varied considerably from one patient to another. In one patient blood pressure decreased well with $5 \mathrm{mg}$. of KK-25-S, whereas another patient showed no significant blood pressure change even after as much as $40 \mathrm{mg}$. Three patients revealed good responsiveness to the drug but others did not show any appreciable responses. There was no significant difference as to the severity of hypertention between ones who responded well and not.

Postural differences of decreased blood pressure were found to be relatively small. One patient who received $30 \mathrm{mg}$. of KK-25-S complained of blurring of vision, and another patient experienced a feeling of weakness after $40 \mathrm{mg}$. of the drug, although no blood pressure reduction was recognizable in these 2 patients. In Fig. 1, a case with a good blood pressure response after single oral dose of $15 \mathrm{mg}$. of $\mathrm{KK}-25-\mathrm{S}$ is presented. In this case, it was 


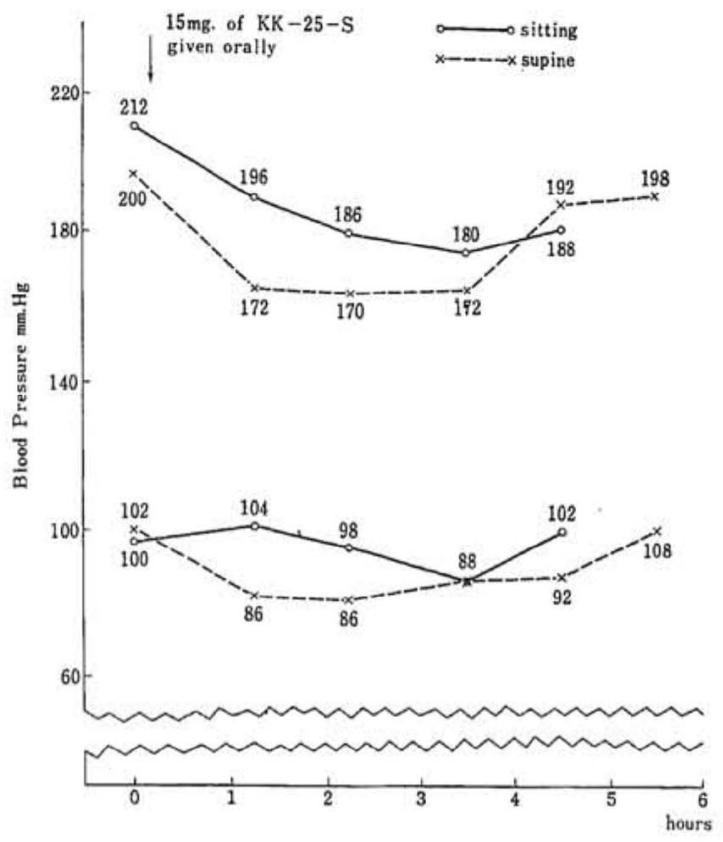

Fig. 1. Blood pressure reduction after $15 \mathrm{mg}$. of oral $\mathrm{KK}-25-\mathrm{S}$ in case C.N.

Table II. Results of the Prolonged Treatment with Oral KK-25-S

\begin{tabular}{|c|c|c|c|c|c|c|}
\hline & \multicolumn{3}{|c|}{ No. of patients } & \multirow{2}{*}{$\begin{array}{l}\text { Percentage of } \\
\text { effective cases }\end{array}$} & \multirow{2}{*}{$\begin{array}{c}\text { Dosage } \\
\text { mg. per day }\end{array}$} & \multirow{2}{*}{$\begin{array}{c}\text { Duration of } \\
\text { treatment } \\
\text { wks. }\end{array}$} \\
\hline & Total & Effective & Not effective & & & \\
\hline Group I & 9 & 2 & 7 & 11 & $30-150$ & $2-13$ \\
\hline Group II & 26 & 20 & 6 & 77 & $\mid \begin{array}{c}15-160 \\
\text { (average in ef- } \\
\text { fective cases 62.5) }\end{array}$ & $2-29$ \\
\hline
\end{tabular}

demonstrated that postural change in blood pressure was not remarkable.

B) Continuous Treatment with KK-25-S

Results of the prolonged treatment with continuous oral KK-25-S were summarized in Table II.

Effect on Blood Pressure :

When treated with KK-25-S alone (Group I), significant blood pressure reduction could be maintained effectively in only 2 of 9 patients. On the other hand, when KK-25-S was combined with other hypotensive drugs (Group II), 20 of 26 patients showed good hypotensive responses which were maintained well throughout the observed periods. Thus the percentage of cases in which effective blood pressure control was successfully maintained was much greater in the latter group (77 per cent vs. 11 per cent). In Group 
I, daily dosage of KK-25-S ranged from 30 to $150 \mathrm{mg}$.; in 2 cases whose blood pressure was effectively controlled, the drug was given in amount of $30 \mathrm{mg}$. and $60 \mathrm{mg}$. per day respectively. In Group II, daily requirements of KK-25-S were in the range of 15 to $160 \mathrm{mg}$.; an average in effective cases was $62.5 \mathrm{mg}$. Amounts of drugs given in combination with KK-25-S are listed in Table III.

Table III. Drugs Given in Combination with KK-25-S

\begin{tabular}{l|cc}
\hline Drugs combined with KK-25-S & No. of patients & $\begin{array}{c}\text { Dosage } \\
\text { mg. per day }\end{array}$ \\
\hline Rauwolfia alkaloids & 21 & $0.5-1.0$ \\
Reserpine & 5 & $4-8$ \\
Alseroxylon & & \\
\hline Benzothiadiazine compounds & 2 & $250-500$ \\
$\quad \begin{array}{l}\text { Chlorothiazide } \\
\text { Flumethiazide }\end{array}$ & 1 & 500 \\
Hydrochlorothiazide & 1 & 75 \\
Benzydroflumethiazide & 6 & $2.5-10$ \\
Hydralazine & 14 & $50-250$
\end{tabular}

Side-Effects :

Side-effects seen during prolonged treatment with KK-25-S are listed in Table IV. Most of them seemed to be due to parasympathetic blockade. Constipation was encountered in 6 patients ( 3 in Group I and 3 in Group II), which was most frequent but was readily relieved with the aid of laxatives. Blurring of vision due to impaired accommodation and mydriasis was seen in

Table IV. Side-Effects in Patients Treated with KK-25-S

\begin{tabular}{|c|c|c|c|c|}
\hline & & & No. of patients & $\begin{array}{c}\text { Dosage of KK-25-S } \\
\text { mg. per day }\end{array}$ \\
\hline Group & I & Constipation & 3 & $60-150$ \\
\hline \multirow{8}{*}{ Group } & \multirow{8}{*}{ II } & Constipation & 3 & $30-90$ \\
\hline & & $\begin{array}{l}\text { Blurring of } \\
\text { vision }\end{array}$ & 2 & $45-90$ \\
\hline & & Diarrhea & 2 & $90-120$ \\
\hline & & $\begin{array}{l}\text { Dryness of the } \\
\text { mouth }\end{array}$ & 1 & 75 \\
\hline & & $\begin{array}{l}\text { Postural } \\
\text { hypotension }\end{array}$ & 2 & $75-90$ \\
\hline & & Dizziness & 1 & 90 \\
\hline & & Headache & 1 & 45 \\
\hline & & $\begin{array}{l}\text { Transient } \\
\text { disturbance of } \\
\text { consciousness }\end{array}$ & 1 & 30 \\
\hline
\end{tabular}


2 patients, diarrhea in 2, dryness of the mouth in one, and headache in one. Marked postural hypotension was seen in only 2 patients, one of whom complained of dizziness at the same time. One patient had an episode of transient disturbance of consciousness while taking the drug at home. Whether this should be attributed to the drug or not was unknown. Side-effects disappeared rapidly when the drug was withdrawn or dosage was decreased.

Development of Drug Tolerance:

The development of tolerance was observed in 3 cases of Group I and in 3 of Group II. In these patients blood pressure which had once come down with KK-25-S was again elevated and requirement of the drug icreased. The tolerance appeared to develop within 2 to 4 weeks after initiation of the treatment.

Severity of the Disease and Efficacy of the Drug:

As shown in Table V, effectiveness appeared to be greater in cases with retinal findings of Grade 1 and smaller in cases of Grade 3 according to the classification of Keith and Wagener. ${ }^{4)}$

Table V. Retinal Findings and Efficacy of KK-25-S

\begin{tabular}{c|c|c|c}
\hline \multirow{2}{*}{ Retinal findings } & \multicolumn{3}{|c}{ No. of patients } \\
\cline { 2 - 4 } & Effective & Not effective & Total \\
\hline Grade 1 & 3 & 0 & 3 \\
Grade 2 & 12 & 6 & 18 \\
Grade 3 & 3 & 5 & 8 \\
\hline Total & 18 & 11 & 29 \\
\hline
\end{tabular}

Table VI. Renal Function and Efficacy of KK-25-S

\begin{tabular}{|c|c|c|c|c|}
\hline & & \multicolumn{3}{|c|}{ No. of patients } \\
\hline & & Effective & Not effective & Total \\
\hline \multirow{2}{*}{ RBF } & $\underset{(>600 \mathrm{ml} . / \mathrm{min} .)}{\text { Normal }}$ & 6 & 6 & 12 \\
\hline & $\begin{array}{c}\text { Subnormal } \\
(<600 \mathrm{ml} . / \mathrm{min} .)\end{array}$ & 4 & 4 & 8 \\
\hline \multirow{2}{*}{ GFR } & $\begin{array}{c}\text { Normal } \\
(>60 \mathrm{ml} . / \mathrm{min} .)\end{array}$ & 5 & 5 & 10 \\
\hline & $\begin{array}{c}\text { Subnormal } \\
(<60 \mathrm{ml} . / \mathrm{min} .)\end{array}$ & 5 & 5 & 10 \\
\hline
\end{tabular}

In 20 patients in whom renal function tests were performed by means of PAH clearance and endogenous creatinine clearance methods, no difference was observed with regard to efficacies among the patients with normal and subnormal renal function (Table VI).

Comparison with Other Ganglionic Blocking Agents: 
Hypotensive potencies of different ganglionic blocking agents were compared with that of $\mathrm{KK}-25-\mathrm{S}$ in regard to daily dosage required to maintain comparable blood pressure reduction. For this purpose, patients were treated with KK-25-S and other drugs alternatively. Results were summarized in Table VII.

Table VII. Comparison of Daily Requirements of Different Ganglionic Blocking Agents

\begin{tabular}{|c|c|c|c|c|}
\hline $\begin{array}{l}\text { Ganglionic blocking } \\
\text { agents compared with } \\
\text { KK-25-S }\end{array}$ & $\begin{array}{c}\text { No. of } \\
\text { patients }\end{array}$ & $\begin{array}{l}\text { Dosage of } \\
\text { KK-25-S } \\
\text { mg.per day }\end{array}$ & $\begin{array}{c}\text { Dosage required for } \\
\text { same degree of } \\
\text { hypotensive effect } \\
\text { mg. per day }\end{array}$ & $\begin{array}{l}\mathrm{KK}-25-\mathrm{S} \text { equivalent to } \\
1 \mathrm{mg} \text {. of the drug } \\
\mathrm{mg} \text {. (average) }\end{array}$ \\
\hline Hexamethonium & 4 & $30-75$ & $200-1,000$ & $0.03-0.23(0.12)$ \\
\hline Pentolinium & 8 & $45-120$ & $50-200$ & $0.4-1.0 \quad(0.76)$ \\
\hline $\begin{array}{c}\text { Trimethidinium } \\
\text { methosulfate }\end{array}$ & 3 & $15-75$ & $30-60$ & $0.5-1.5 \quad(1.0)$ \\
\hline Pempidine & 8 & $15-140$ & $2.5-10$ & 6. $-20 .(12.1)$ \\
\hline Mecamylamine & 2 & $75-90$ & $5-10$ & 9. -15. $(12.0)$ \\
\hline
\end{tabular}

Daily requirements of KK-25-S were compared with those of hexamethonium in 4 patients. Amounts of $\mathrm{KK}-25-\mathrm{S}$ equivalent to $1,000 \mathrm{mg}$. of hexamethonium were observed to be within a range of 30 to $230 \mathrm{mg}$., with an average of $120 \mathrm{mg}$. Amounts of $\mathrm{KK}-25-\mathrm{S}$ equivalent to $10 \mathrm{mg}$. of pentolinium estimated in 8 patients were found to be ranged from 4 to $10 \mathrm{mg}$., averaging $7.6 \mathrm{mg}$. Amounts of KK-25-S necessary for maintaining approximately the same degree of blood pressure reduction with $10 \mathrm{mg}$. of trimethidinium were 5 to $15 \mathrm{mg}$. in 3 patients, and the mean was $10 \mathrm{mg}$. Equivalency of KK-25-S to pempidine was attempted to determine in 11 patients, and in 8 of them comparable blood pressure reduction was achieved. In these comparable cases, it was estimated that 6 to $20 \mathrm{mg}$. of $\mathrm{KK}-25-\mathrm{S}$, averaging 12.1 mg., was equivalent to $1 \mathrm{mg}$. of pempidine. In this manner, amounts of KK-25-S equivalent to $1 \mathrm{mg}$. of mecamylamine in 2 patients were found to be 9 and $15 \mathrm{mg}$. with a mean of $12 \mathrm{mg}$.

\section{Discussion}

Experimental investigations on the pharmacologic activities of KK-25$\mathrm{S}$ have shown that the drug possesses a potent ganglionic blocking action with a long duration and less toxicity, and that the drug is relatively well absorbed from the gastrointestinal tract after the oral administration. In the present study, therapeutic usefulness of KK-25-S for the treatment of hypertension is evaluated on the basis of the results obtained in our clinical trials.

Data on the single dose administration suggest that the drug should be given in 3 or 4 divided doses in order to achieve a continuous blood pressure 
reduction throughout a day. Individual responsiveness to the drug varied considerably from patient to patient, as is often the case with other antihypertensive drugs. Daily dosage therefore should be carefully determined in each case according to the patient's response. Initial dosage of KK-25-S is recommended as much as 15 to $20 \mathrm{mg}$. per day which is gradually increased until satisfactory blood pressure reduction is achieved.

Treatment with KK-25-S alone failed to maintain sufficient and continuous blood pressure reduction in 7 of 9 patients. In contrast, combination with other drugs such as Rauwolfia, hydralazine and benzothiadiazine compounds resulted in good hypotensive effect in 20 of 26 patients. It may be suggested that hypotensive responses are augmented by additional and synergistic actions of these drugs. It has been also noted that ganglionic blockade is potentiated by saluretic action of benzothiadiazine compounds. ${ }^{5)}$ The development of drug tolerance was less frequent in Group II, indicating that combination with other drugs might prevent the development of the tolerance. This evidence may also be contributed for the greater efficacy in combined therapy.

Side-effects of the drug observed in our patients were similar to those seen with other ganglionic blocking agents. Most of these side-effects seemed to be due to parasympathetic blockade. Constipation was most frequent but was readily relieved with laxatives. Side-effects were subsided rapidly when the drug was withdrawn or reduced in dosage.

The observed fact that postural hypotension was relatively infrequent and slight in degree is considered to be of great advantage. It might be likely that the drug should possess certain central action as having been suggested with trimethidinium methosulfate. ${ }^{6)}$

Although the use of KK-25-S is indicated for moderately severe or severe hypertension, need for careful precautions should be emphasized when the drug is given to patients with advanced disease. It is especially true when circulatory insufficiencies in vital organs are suspected. One patient had an episode of transitory unconsciousness while taking the drug though it was unknown whether the accident was attributable to cerebral circulatory failure due to excessive hypotension.

Observations on efficacy of the drug and severity of the disease classified according to retinal findings demonstrate that effectiveness of the drug is greater in early cases than in advanced cases. No difference in efficacies was recognizable among patients with normal and subnormal renal function. In this respect, it should be considered that no patient with marked renal failure was included in our study.

Comparative studies on hypotensive potencies were made among different ganglionic blocking agents, and it may be concluded as follows: KK-25-S is approximately 10 times as potent as hexamethonium; it is about one and a half times as potent as pentolinium; almost equivalent to equal dose of trimethidinium methosulfate; and the hypotensive potency of KK-25-S is 
about a tenth of those with mecamylamine and pempidine.

\section{Summary}

Antihypertensive effect of KK-25-S, a new potent ganglionic blocking agent, was evaluated in patients with moderate to severe essential hypertension.

(1) Hypotensive responses after single oral dose of 5 to $40 \mathrm{mg}$. of the drug were tested in 7 hypertensive subjects. Significant reduction of blood pressure was observed to occur within one or 2 hours and persisted for 4 hours or more.

(2) Thirty-two patients were treated with KK-25-S for periods of 2 to 29 weeks. Seven of 9 patients treated with KK-25-S alone failed to maintain significant hypotensive effect. But in 20 of 26 patients who received KK-25-S combined with other hypotensive drugs, significant blood pressure reduction was maintained throughout the treatment.

(3) Side-effects of the drug due to parasympathetic blockade were seen but readily controlled. Postural hypotension was relatively infrequent and slight in degree.

(4) The hypotensive potency of KK-25-S was compared with those of different ganglionic blocking agents.

It is concluded that KK-25-S is a potent hypotensive drug and useful for the treatment of hypertension.

\section{REFERENCES}

1. Finnerty, F. A., Jr. and Fries, E. D.: Circulation 2: 828, 1950.

2. Smirk, F. H.: Lancet 1: 457, 1953.

3. Takeda, K., Kitahonoki, K., Mineshita, T., Kido, R., and Ikeda, T. : Jap. Heart J. 1: 198, 1960.

4. Keith, N. M., Wagener, H. P., and Barker, N. W. : Am. J. Med. Sci. 197: 332, 1939.

5. Heider, C., Dennis, E., and Moyer, J. H. : Ann. New York Acad. Sci. 71: 456, 1958.

6. Dunsmore, R. A., Dunsmore, L. D., Goldman, A., Elias, M., and Warner, R. S.: Am. J. Med. Sci. 236: 483, 1958. 